\title{
Microstructure and Mechanical Properties of Heterogeneous Ceramic-Polymer Composite Using Interpenetrating Network
}

\author{
Eun-Hee Kim, ${ }^{1}$ Yeon-Gil Jung, ${ }^{1}$ and Chang-Yong Jo ${ }^{2}$ \\ ${ }^{1}$ School of Nano \& Advanced Materials Engineering, Changwon National University, Changwon, \\ Kyungnam 641-773, Republic of Korea \\ ${ }^{2}$ High Temperature Materials Research Group, Korea Institute of Materials Science, Changwon, Gyeongnam 641-831, Republic of Korea \\ Correspondence should be addressed to Eun-Hee Kim, udam99@changwon.ac.kr and Yeon-Gil Jung, jungyg@changwon.ac.kr
}

Received 5 March 2012; Accepted 22 March 2012

Academic Editor: Sevan P. Davtyan

Copyright (C) 2012 Eun-Hee Kim et al. This is an open access article distributed under the Creative Commons Attribution License, which permits unrestricted use, distribution, and reproduction in any medium, provided the original work is properly cited.

\begin{abstract}
Prepolymer, which can be polymerized by a photo, has been infiltrated into a porous ceramic to improve the addition effect of polymer into the ceramic, as a function of the functionality of prepolymer. It induces the increase in the mechanical properties of the ceramic. The porous alumina $\left(\mathrm{Al}_{2} \mathrm{O}_{3}\right)$ and the polyurethane acrylate (PUA) with a network structure by photo-polymerization were used as the matrix and infiltration materials, respectively. The porous $\mathrm{Al}_{2} \mathrm{O}_{3}$ matrix without the polymer shows lower values in fracture strength than the composites, since the stress is transmitted more quickly via propagation of cracks from intrinsic defects in the porous matrix. However, in the case of composites, the distribution of stress between heterophases results in the improved mechanical properties. In addition, the mechanical properties of composites, such as elastic modulus and fracture strength, are enhanced with increasing the functionality of prepolymer attributed to the crosslinking density of polymer.
\end{abstract}

\section{Introduction}

Porous alumina $\left(\mathrm{Al}_{2} \mathrm{O}_{3}\right)$ has been widely used as hot gas filtration, catalyst support, filtration for heavy metal ions in water, chromatography, and fine or microchannels for electrophoresis, owing to its excellent physical and chemical properties such as acid resistance and chemical stability $[1,2]$. However, its use in practical applications has been impeded by its naturally low mechanical property, which has been a bottleneck in the scientific and technological point of view. Therefore, a ceramic-polymer composite has been introduced as a new class of construction and functional materials for industrial applications, which can combine the hardness and stiffness of ceramic and the rubber elasticity of polymer [3-7]. De Salazar et al. has studied the mechanical properties of composites fabricated with the cellular ceramic ( $\mathrm{SiC}$ and $\mathrm{SiO}_{2} \cdot \mathrm{ZrO}_{2}$ ) and the epoxy resin, as a function of cell size [8]. Brandt et al. has researched the novel ceramicpolymer composites through polymer-encapsulated $\mathrm{TiO}_{2}$ nanoparticles [9]. However, the composite with the $\mathrm{TiO}_{2}$ shows low mechanical properties, resulting from the nosintering of composite due to the heat treatment at the relatively low temperature. In addition, various works related to the mechanical properties of ceramic-polymer composites affected by elasticity of polymer used as a reinforcement material have not been researched yet.

Therefore, in this work, to effectively increase the mechanical properties of porous ceramic, two key points have been considered in the fabrication of desirable composite. One is to use the prepolymer which has extremely lower viscosity than polymer. Polymer has generally a gel phase of high viscosity due to the long chain by join with a lot of monomers, deteriorating the dispersibility of polymer into matrix. Therefore, the prepolymer of a sol phase, which can be polymerized by a photo, has been infiltrated into the porous ceramic to maximize the addition effect of polymer into the ceramic matrix. This interpenetrating network (IPN) method increases the universal properties of the ceramic matrix by the homogeneous dispersion of prepolymer into the ceramic matrix. Namely, it is far preferable to incorporate the polymer into the ceramic matrix by covalent bonding between polymer chains than by simply mixing them by shear. The ultraviolet (UV) curing used in this work is one of well-known photopolymerization methods 
and has been employed at various industrial applications. Its advantages include energy savings, and it yields products with high durability and high scratch resistance. The other is to use polyurethane (PU) which easily changes the elastic modulus of polymer controlled by crosslinking density. PU is the most versatile polymer material, leading to its use in many different applications, for example, in building materials, sports goods, medical equipment, adhesives, and coatings [10-12]. Consequently, the prepolymer infiltrated in the porous matrix has been polymerized by free-radical photopolymerization as a function of the functionality of prepolymer, in efforts to increase the mechanical properties, such as elastic modulus and fracture strength. The microstructure and mechanical properties of the prepared PUA- $\mathrm{Al}_{2} \mathrm{O}_{3}$ composites have been observed and measured, respectively, using various analytical techniques.

\section{Experimental Procedure}

The polyurethane acrylate (PUA) oligomers were synthesized from polypropylene glycol (PPG Mn $=300$, Sigma-Aldrich Korea, Yongin, Republic of Korea) and hexamethylene diisocyanate (HDI, Sigma-Aldrich Korea, Yongin, Republic of Korea) to form isocyanate-terminated prepolymer. PPGs were dried at $80^{\circ} \mathrm{C}$ with $0.1 \mathrm{~mm} \mathrm{Hg}$ for several hours until no bubbling was observed. Extra pure grade of HDI was used without further purification. A molar excess of HDI was reacted with PPG for over $1 \mathrm{~h}$ at $80^{\circ} \mathrm{C}$ to obtain HDI-terminated prepolymer. Then, the reacted mixture was cooled down to $40^{\circ} \mathrm{C}$, and hydroxyethyl methacrylate (HEMA, Sigma-Aldrich Korea, Yongin, Republic of Korea) was added to obtain HEMA-capped urethane oligomer [13]. Completion of the reaction was confirmed by the disappearance of NCO peak at $2270 \mathrm{~cm}^{-1}$ in the Fourier transform infrared spectroscopy (FT-IR) analysis.

The polymer used in this work was prepared from a homogeneous prepolymer mixture consisting of the PUA oligomer, the reactive diluent, namely, $\mathrm{N}$-vinylpyrrolidone (NVP, Sigma-Aldrich Korea, Yongin, Republic of Korea), and 2-hydroxy-2-methyl-1-phenyl propane-1-one (Darocur 1173, Ciba in Korea, Seoul, Republic of Korea) as a photoinitiator. The prepolymer compositions were fixed at $1 / 1$ and $3 / 1$ (oligomer/NVP) by weight ratio to investigate the effect of crosslinking density of polymer. The green body of ceramic matrix was prepared by an uniaxial pressing process with $\mathrm{Al}_{2} \mathrm{O}_{3}$ powder, and then the prepared green body was heat treated at $1000^{\circ} \mathrm{C}$ for $1 \mathrm{~h}$. At room temperature, the mixed prepolymer was infiltrated into the $\mathrm{Al}_{2} \mathrm{O}_{3}$ matrix in a vacuum chamber for the homogeneous infiltration of prepolymer mixture into all pores of ceramic matrix. The prepolymer-infiltrated matrix was cured by UV light $\left(1.5 \mathrm{~mW} / \mathrm{cm}^{2}, 365 \mathrm{~nm}\right)$ for $3 \mathrm{~min}$. The synthetic scheme for the PUA- $\mathrm{Al}_{2} \mathrm{O}_{3}$ composite is given in Figure 1, and the basic formulations employed to prepare PUA film and PUA- $\mathrm{Al}_{2} \mathrm{O}_{3}$ composites are shown in Tables 1 and 2, respectively.

Dynamic mechanical properties of the polymer films were measured using DMTA (Rheometric Scientific MK) at a heating rate of $4^{\circ} \mathrm{C} / \mathrm{min}$ and $10 \mathrm{~Hz}$. The difference before and after the polymerization of PUA and the presence of PUA

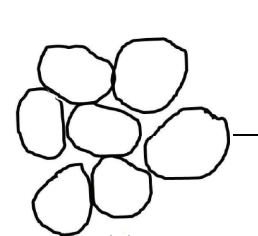

(1)
Porous alumina Infiltration of prepolymer

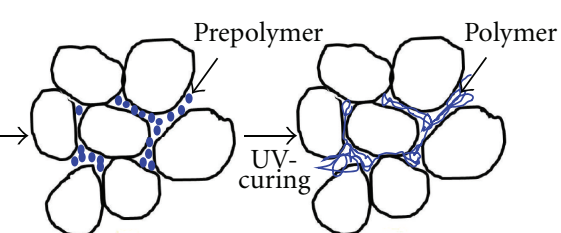

(2)
Ceramic-polymer composite

FIgURE 1: Schematic diagram for fabricating PUA- $\mathrm{Al}_{2} \mathrm{O}_{3}$ composites.

TABLe 1: Formulations used to prepare prepolymers and stressstrain results of PUA films.

\begin{tabular}{lcccc}
\hline $\begin{array}{l}\text { Prepolymer } \\
\text { type }\end{array}$ & $\begin{array}{c}\text { Oligomer/NVP } \\
(\mathrm{mol} \%)\end{array}$ & $\begin{array}{c}\text { Functionality } \\
\left(F_{\text {av }}\right)\end{array}$ & $\begin{array}{c}\text { Elongation } \\
(\%)\end{array}$ & $\begin{array}{c}\text { Tensile } \\
\text { strength } \\
(\mathrm{MPa})\end{array}$ \\
\hline Type 1 & $1 / 1$ & 1.5 & 25 & 10 \\
Type 2 & $3 / 1$ & 1.75 & 13 & 18 \\
\hline
\end{tabular}

TABle 2: Formulations to prepare PUA- $\mathrm{Al}_{2} \mathrm{O}_{3}$ composites and the mechanical properties of composites pepared.

\begin{tabular}{lcccc}
\hline $\begin{array}{l}\text { Run } \\
\text { number }\end{array}$ & $\begin{array}{c}\text { Oligomer/NVP } \\
(\text { mol \%) }\end{array}$ & $\begin{array}{c}\text { Ceramic } \\
\text { matrix }\end{array}$ & Porosity $(\%)$ & $\begin{array}{c}\text { Hardness } \\
(\mathrm{GPa})\end{array}$ \\
\hline Run 1 & - & & 36.0 & $1.35 \pm 0.13$ \\
Run 2 & $1 / 1$ & $\mathrm{Al}_{2} \mathrm{O}_{3}$ & 28.4 & $1.49 \pm 0.30$ \\
Run 3 & $3 / 1$ & & 14.6 & $1.40 \pm 0.33$ \\
\hline
\end{tabular}

in $\mathrm{Al}_{2} \mathrm{O}_{3}$ matrix were analyzed using a Fourier transform infrared spectrometer (Nicolet, Thermo Fisher Scientific, MA, USA). The microstructure of composite was observed using a scanning electron microscope (SEM; JEOL Model JSM-5610, Tokyo, Japan). The porosity of composite was measured by mercury porosimeter (AutoPore Iv berries, Micromeritics GmbH, Rutherford, NJ, USA). The fracture strength and elastic modulus of PUA- $\mathrm{Al}_{2} \mathrm{O}_{3}$ composite were measured with a universal testing machine (UTM, Instron 5566, Instron Corp., Norwood, MA, USA) in the bending mode at a rate of $0.5 \mathrm{~mm} \mathrm{~min}^{-1}$. The hardness values of composites were measured using a Vickers indenter (HM122, Mitutoyo Corp., Japan), with a load of $10 \mathrm{~N}$. All tests were conducted at room temperature, and at least five runs were performed.

\section{Results and Discussion}

3.1. Synthesis and Mechanical Properties of PUA. Chemical reaction of photopolymerization of PUA measured by FTIR is shown in Figure 2. The peak at about $1650 \mathrm{~cm}^{-1}$ corresponding to the stretch vibration of vinyl groups almost disappears after the UV-curing, indicating that the prepolymer is converted into the polymer with a long chain. Network polymer is generally formed by the reaction between intermolecules or intramolecules with vinyl group during photopolymerization. Therefore, the functionality represented to the average number of vinyl group per 


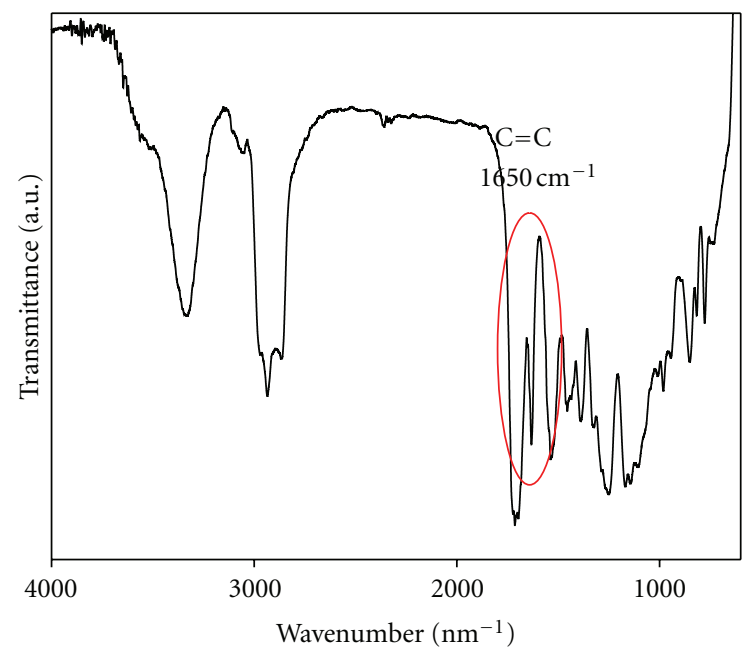

(a)

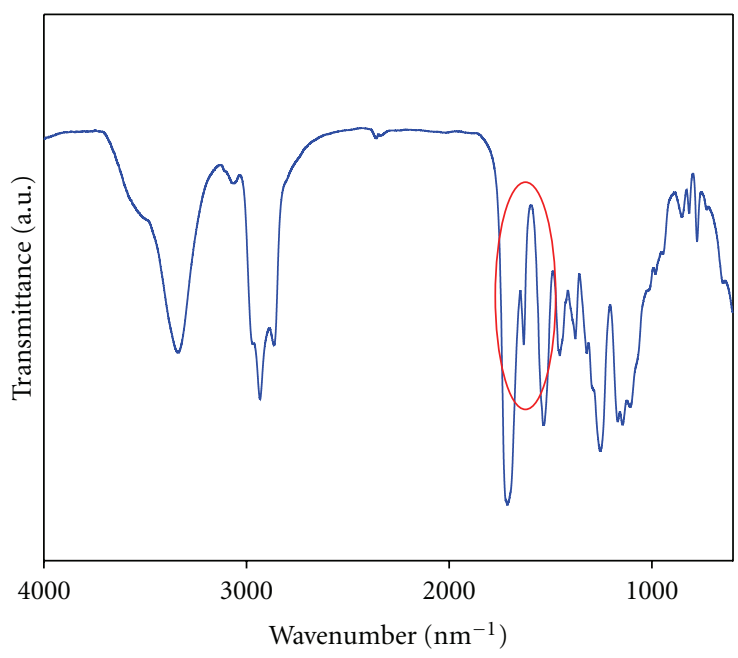

(b)

FIGURE 2: IR analysis of PUA films (a) before and (b) after polymerization.

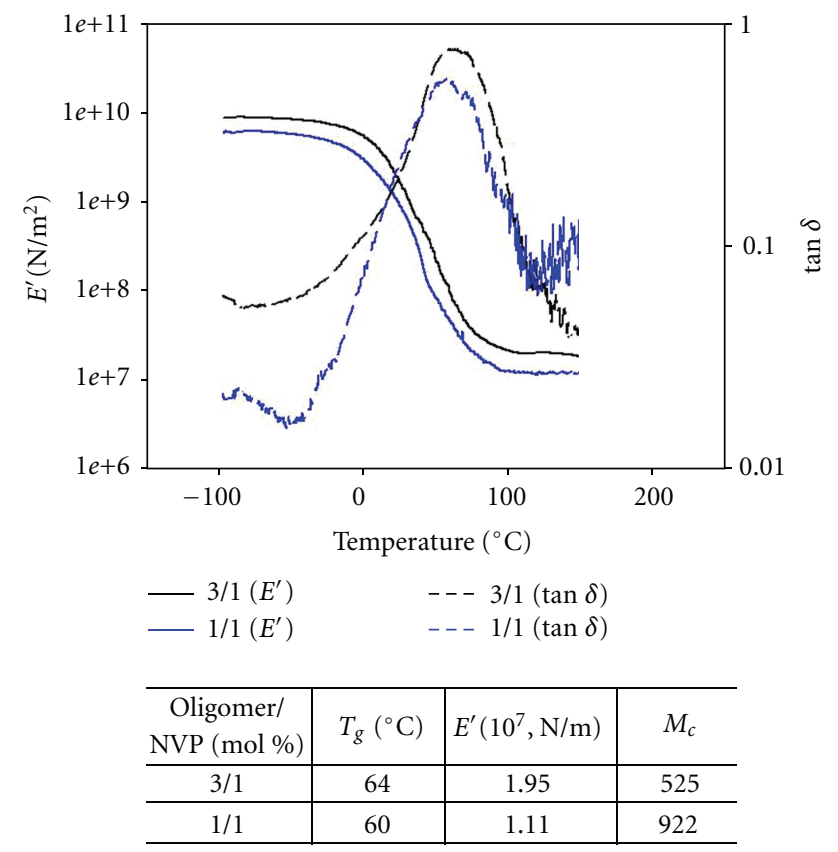

FIgURE 3: Storage modulus of PUA films as a function of prepolymer composition.

a molecule is important factor for increasing the crosslinking density of polymer, leading to the enhancement of the storage modulus and glass transition temperature $\left(T_{g}\right)$ of polymer film. In this work, the functionality of prepolymer is controlled by the composition ratio between PUA with two acrylate groups $\left(F_{i}=2\right)$ and NVP with five-numbered cyclic group attached to the vinyl carbon $\left(F_{i}=1\right)$. The average functionality $\left(F_{\mathrm{av}}\right)$ of prepolymer is determined by the following equation:

$$
F_{\mathrm{av}}=\Sigma \varphi_{i} F_{i}
$$

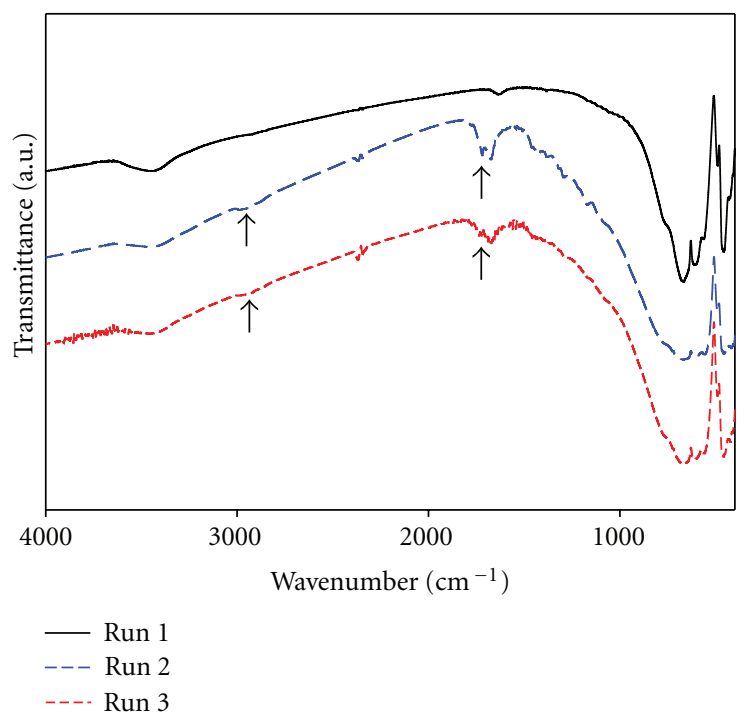

FIgURE 4: IR analysis of PUA- $\mathrm{Al}_{2} \mathrm{O}_{3}$ composites prepared with different prepolymer compositions. Arrows at $2800 \mathrm{~cm}^{-1}$ and $1700 \mathrm{~cm}^{-1}$ indicate the $\mathrm{C}-\mathrm{H}$ aliphatic and conjugated $\mathrm{C}=\mathrm{O}$ groups, respectively.

where $\varphi_{i}$ is the mole fraction of prepolymer having functionality $\left(F_{i}\right)$. The functionality of each prepolymer is shown in Table 1. Therefore, the prepolymer with $F_{\mathrm{av}}=1.75$ has higher crosslinking density than that with $F_{\mathrm{av}}=1.5$.

Typical dynamic behaviors in mechanical properties of the neat polymer films are shown in Figure 3 as a function of prepolymer composition. Regardless of prepolymer composition, the storage modulus curve shows a single point of inflection corresponding to the glass transition temperature $\left(T_{g}\right)$. This indicates that the urethane acrylate and NVP segments are phase-mixed at a segment level. When two segments are immiscible, generally two discrete $T_{g}$ values 

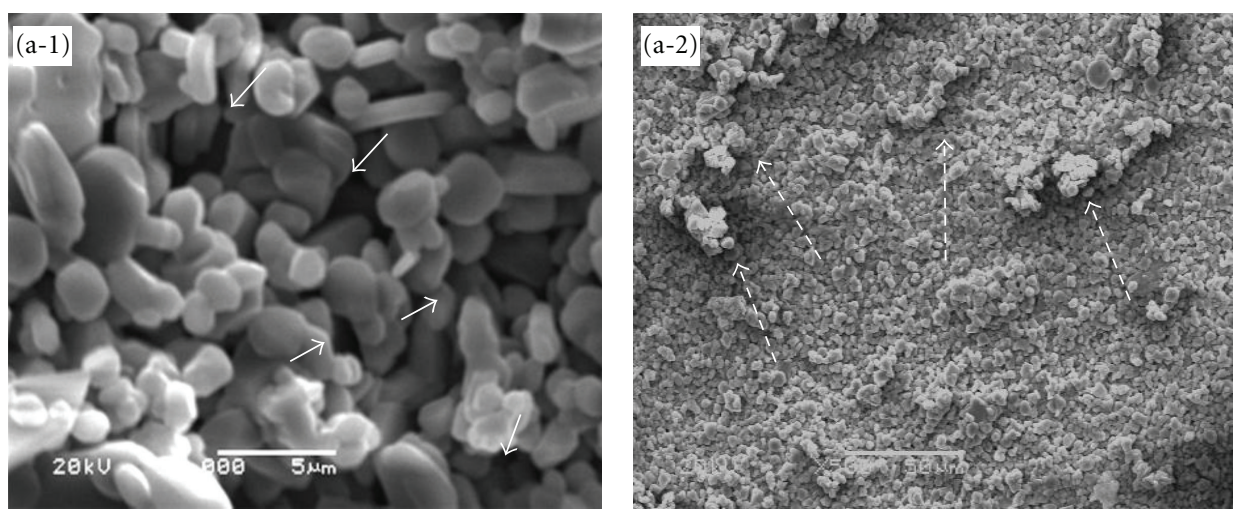

(a)
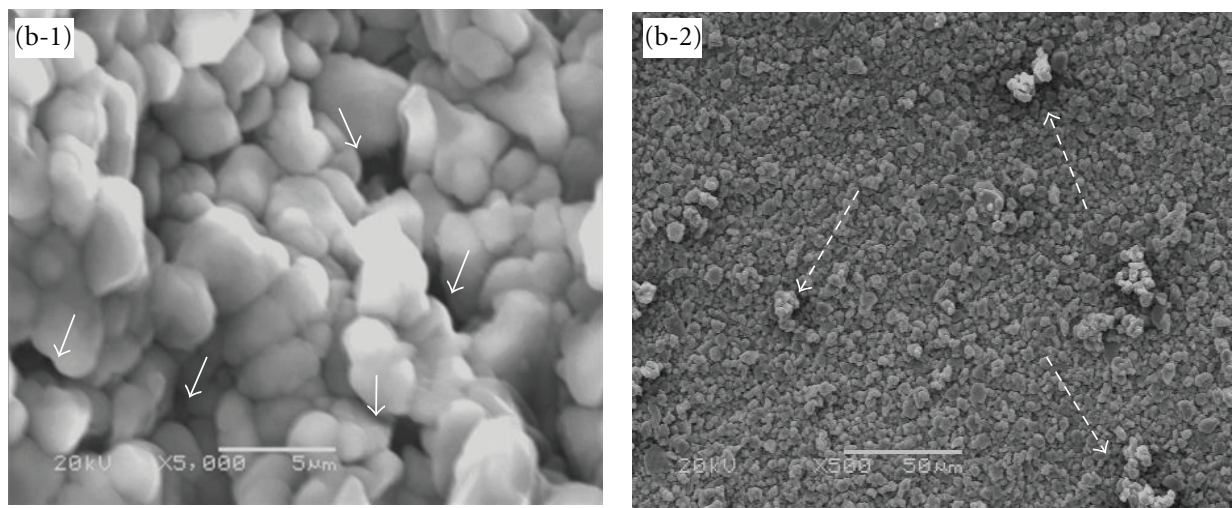

(b)
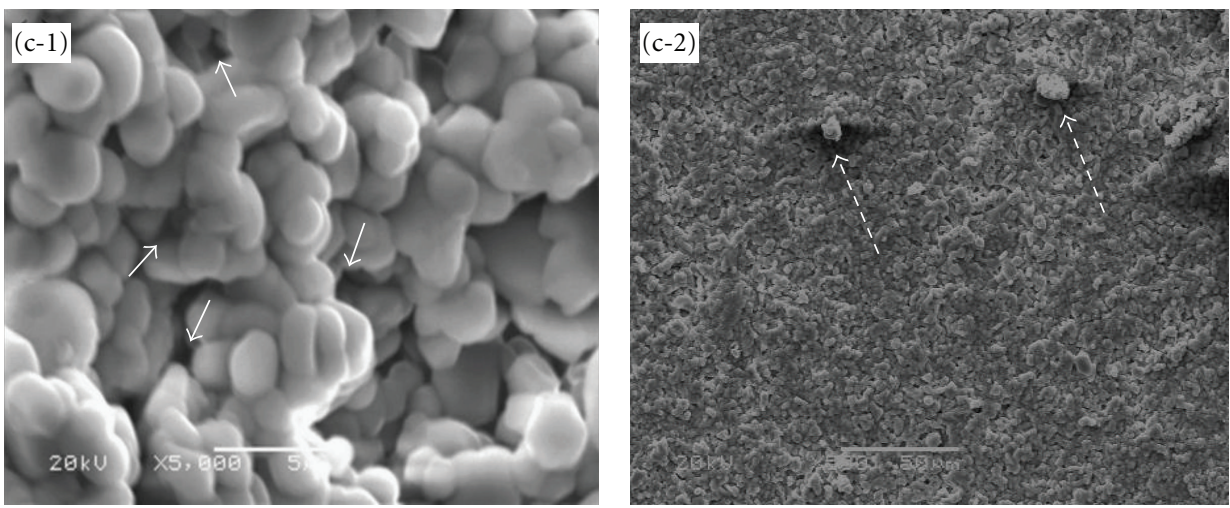

(c)

FIGURE 5: Microstructures at fracture surfaces of PUA- $\mathrm{Al}_{2} \mathrm{O}_{3}$ composites as a function of prepolymer composition: (a) run 1, (b) run 2, and (c) run 3. Each number indicates the high and low magnifications, respectively.

will be obtained. The elastic modulus in the rubbery state and the $T_{g}$ of polymer film increase with increasing the functionality of prepolymer. Namely, it is due to the augment of crosslinking density of polymer. Since the polymers are networked, as evidenced by the existence of a rubbery plateau, the molecular weight between crosslinks $\left(M_{c}\right)$ can be calculated based on the ideal rubber theory given by

$$
E_{N}^{o}=3 \frac{\rho R T}{M_{c}}
$$

where $\rho, R, T$, and $E_{N}^{o}$ are density $\left(1.1 \mathrm{~g} / \mathrm{cm}^{3}\right)$, gas constant $\left(8.314 \mathrm{~m}^{3} \cdot \mathrm{Pa} / \mathrm{mol} \cdot \mathrm{K}\right)$, absolute temperature $(373 \mathrm{~K})$, and the plateau modulus, respectively $[14,15]$. Using $\rho=1.1 \mathrm{~g} / \mathrm{cm}^{3}$ and plateau values of Figure $3, M_{c}$ was calculated (see the table in the Figure 3). $M_{c}$ is decreased from 922 to 525 with increasing the functionality of prepolymer, inducing the increase in the $T_{g}$ and elastic modulus $\left(E^{\prime}\right)$ of polymer film.

The stress-strain behavior of the neat polymer films prepared with different compositions of prepolymer is shown in Table 1. The tensile strength of polymer films is enhanced with increasing the functionality of prepolymer, 


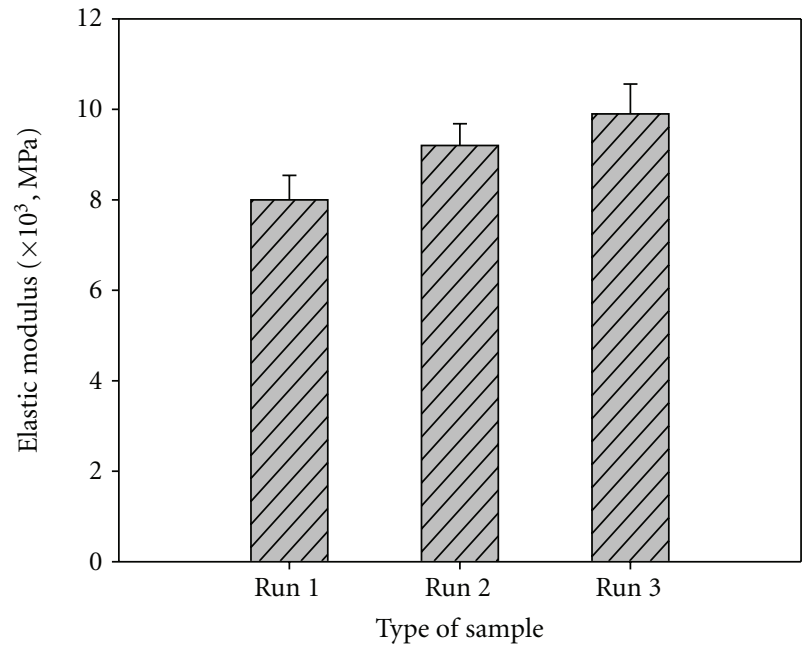

(a)

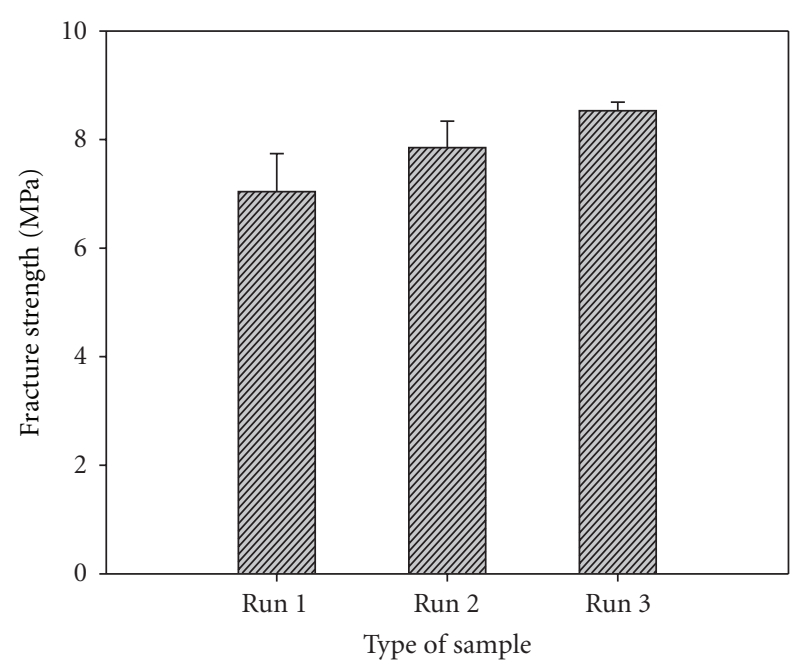

(b)

FIgURE 6: Mechanical properties of PUA- $\mathrm{Al}_{2} \mathrm{O}_{3}$ composites as a function of prepolymer composition: (a) modulus and (b) fracture strength.

while the elongation at breaking point decreases, owing to an increase in the crosslinking density. High crosslinking density provides the rigidity in the polymer film and disturbs the chain folding, resulting in the high elastic modulus and the low strain at breaking point in the glassy state.

\subsection{Microstructure and Mechanical Properties of $\mathrm{PUA}-\mathrm{Al}_{2} \mathrm{O}_{3}$} Composites. The presence of PUA in the porous matrix is investigated using FT-IR (Figure 4). In the PUA- $\mathrm{Al}_{2} \mathrm{O}_{3}$ composites (runs 2 and 3), the peaks at $2800 \mathrm{~cm}^{-1}$ and $1700 \mathrm{~cm}^{-1}$ corresponding to the $\mathrm{C}-\mathrm{H}$ aliphatic and conjugated $\mathrm{C}=\mathrm{O}$ groups, respectively, are detected, which are indicated by arrows in Figure 4 . The evidence means that PUA is infiltrated into the porous $\mathrm{Al}_{2} \mathrm{O}_{3}$ matrix because these peaks are shown in PUA molecule.

The microstructures of fracture surfaces in PUA- $\mathrm{Al}_{2} \mathrm{O}_{3}$ composites with different compositions of prepolymer are shown in Figure 5. In the pure $\mathrm{Al}_{2} \mathrm{O}_{3}$ matrix, the $\mathrm{Al}_{2} \mathrm{O}_{3}$ particles are almost distinguishable and independent (Figure 5(a1)), whereas interfaces between $\mathrm{Al}_{2} \mathrm{O}_{3}$ particles in the PUA$\mathrm{Al}_{2} \mathrm{O}_{3}$ composites are continuously connected irrespective of the functionality of prepolymer (Figures 5(b-1) and 5(c-1)). The porosities of composites prepared are shown in Table 2, indicating that the porosity of composite is decreased with the increase of the functionality of polymer infiltrated in the matrix, as shown in SEM morphology of Figure 5. In addition, the size of pore existed in the matrix is significantly reduced in the $\mathrm{PUA}-\mathrm{Al}_{2} \mathrm{O}_{3}$ composites, compared with the pure $\mathrm{Al}_{2} \mathrm{O}_{3}$ matrix, which is indicated with white solid arrows in Figure 5. It is provided that the prepolymer with a low viscosity is well infiltrated into the porous matrix. In the low magnification of Figure 5, the fracture surfaces of the pure $\mathrm{Al}_{2} \mathrm{O}_{3}$ matrix show considerably rough and uneven, compared with those of PUA- $\mathrm{Al}_{2} \mathrm{O}_{3}$ composites. In addition, $\mathrm{Al}_{2} \mathrm{O}_{3}$ particles are remarkably aggregated in the pure $\mathrm{Al}_{2} \mathrm{O}_{3}$ matrix. However, the fracture surfaces of PUA- $\mathrm{Al}_{2} \mathrm{O}_{3}$ composites become smooth and the aggregation between
$\mathrm{Al}_{2} \mathrm{O}_{3}$ particles is gradually declined with increasing the functionality of prepolymer. Namely, SEM images investigate a good adhesion of the polymer to the ceramic matrix. Therefore, in the case of PUA- $\mathrm{Al}_{2} \mathrm{O}_{3}$ composites, the crack propagation through the matrix could be obstructed at the polymer phase [16], improving the mechanical properties in the $\mathrm{PUA}-\mathrm{Al}_{2} \mathrm{O}_{3}$ composites.

The elastic modulus and fracture strength values of PUA- $\mathrm{Al}_{2} \mathrm{O}_{3}$ composites with different compositions of prepolymer are shown in Figure 6. The composite prepared with the prepolymer composition of $3 / 1$ shows the highest fracture strength and elastic modulus of about $8.5 \mathrm{MPa}$ and of about $9.9 \mathrm{GPa}$, respectively. In the case of PUA$\mathrm{Al}_{2} \mathrm{O}_{3}$ composites, the fracture strength and elastic modulus are enhanced, compared with those of the porous $\mathrm{Al}_{2} \mathrm{O}_{3}$ matrix without the polymer. It is owing to the crack energy (stress energy) dispersed by the polymer and the reduction of porosity. Namely, the crack propagating in the matrix is deflected and/or obstructed at the polymer. Also, the fracture strength and elastic modulus are increased with increasing the functionality of polymer. This enhancement is related to the increase in the crosslinking density of polymer. However, hardness is not changed in spite of the addition and functionality of polymer (see Table 2). It is because the polymer is very lower hardness value than the matrix.

\section{Conclusions}

The PUA- $\mathrm{Al}_{2} \mathrm{O}_{3}$ composite has been fabricated by infiltration method to improve the mechanical properties of porous $\mathrm{Al}_{2} \mathrm{O}_{3}$ matrix. Especially, the interpenetrating network (IPN) method, usually used to increase the universal properties of matrix, is introduced to homogeneously disperse the polymer into the matrix, as a function of the functionality of prepolymer. The tensile strength and elasticity of neat polymer films are increased with increasing the functionality of prepolymer related to the crosslinking density. The 
microstructure of fracture surface shows a good adhesion between the polymer and the matrix. The $\mathrm{PUA}-\mathrm{Al}_{2} \mathrm{O}_{3}$ composites have higher values in the fracture strength and elastic modulus than the porous matrix without the polymer, since the crack propagation from intrinsic defects formed at the surface and in the inside matrix is interrupted by the polymer. Therefore, the mechanical properties are improved by the distribution of stress between heterophases in the PUA- $\mathrm{Al}_{2} \mathrm{O}_{3}$ composite and enhanced with increasing the functionality of polymer.

\section{Acknowledgments}

This work was supported by the National Research Foundation of Korea (NRF) Grant funded by the Korean Government (MEST) (2011-0030802), by the Korea Institute of Materials Science (KIMS) in 2012, and by the Changwon National University in 2011.

\section{References}

[1] I. W. M. Brown and W. R. Owers, "Fabrication, microstructure and properties of Fe-TiC ceramic-metal composites," Current Applied Physics, vol. 4, no. 2-4, pp. 171-174, 2004.

[2] A. A. Aal, Z. I. Zaki, and Z. A. Hamid, "Novel composite coatings containing (TiC- $\mathrm{Al}_{2} \mathrm{O}_{3}$ ) powder," Materials Science and Engineering A, vol. 447, no. 1-2, pp. 87-94, 2007.

[3] T. Dingshen, T. Nianxi, X. Qing, and S. Yajun, "Study on surface modification of titanium dioxide using polymethyl methacrylate," Journal of Shanghai University, vol. 2, no. 1, pp. 67-78, 1998.

[4] M. Yang and Y. Dan, "Preparation of poly(methyl methacrylate)/titanium oxide composite particles via in-situ emulsion polymerization," Journal of Applied Polymer Science, vol. 101, no. 6, pp. 4056-4063, 2006.

[5] A. M. de Oliveira, M. L. C. P. da Silva, G. M. Alves, P. C. de Oliveira, and A. M. Dos Santos, "Encapsulation of $\mathrm{TiO}_{2}$ by emulsion polymerization with methyl metacrylate (MMA)," Polymer Bulletin, vol. 55, no. 6, pp. 477-484, 2005.

[6] C. H. M. Caris, L. P. M. van Elven, A. M. van Herk, and A. L. German, "Polymerization of MMA at the surface of inorganic submicron particles," British Polymer Journal, vol. 21, no. 2, pp. 133-140, 1989.

[7] A. Zhu, Z. Shi, A. Cai, F. Zhao, and T. Liao, "Synthesis of coreshell $\mathrm{PMMA}-\mathrm{SiO}_{2}$ nanoparticles with suspension-dispersionpolymerization in an aqueous system and its effect on mechanical properties of PVC composites," Polymer Testing, vol. 27, no. 5, pp. 540-547, 2008.

[8] J. M. G. de Salazar, M. I. Barrena, G. Morales, L. Matesanz, and N. Merino, "Compression strength and wear resistance of ceramic foams-polymer composites," Materials Letters, vol. 60, no. 13-14, pp. 1687-1692, 2006.

[9] K. Brandt, V. Salikov, H. Özcoban et al., "Novel ceramicpolymer composites synthesized by compaction of polymerencapsulated $\mathrm{TiO}_{2}$-nanoparticles," Composites Science and Technology, vol. 72, no. 1, pp. 65-71, 2011.

[10] C. Hapburn, Polyurethane Elastomers, Elsevier, Oxford, UK, 1991.

[11] N. M. K. Lamba, K. A. Woodhous, and S. L. Cooper, Polyurethane in Biomedical Applications, CRC Press, New York, NY, USA, 1998.
[12] C. Deker, "Kinetic study and new applications of UV radiation curing," Macromolecular Rapid Communications, vol. 23, no. 18, pp. 1067-1093, 2002.

[13] E. H. Kim and B. K. Kim, "Diffraction grating in noncrosslinked polymers," Journal of Polymer Science B, vol. 42, no. 4, pp. 613-620, 2004.

[14] B. Yang, H. Xu, J. Wang, S. Gang, and C. Li, "Preparation and thermal property of hybrid nanocomposites by free radical copolymerization of styrene with octavinyl polyhedral oligomeric silsesquioxane," Journal of Applied Polymer Science, vol. 106, no. 1, pp. 320-326, 2007.

[15] A. N. Gent, Engineering with Rubber, Hanser, New York, NY, USA, 1992.

[16] K. Konopka, A. Boczkowska, K. Batorski, M. Szafran, and K. J. Kurzydłowski, "Microstructure and properties of novel ceramic-polymer composites," Materials Letters, vol. 58, no. 30, pp. 3857-3862, 2004. 

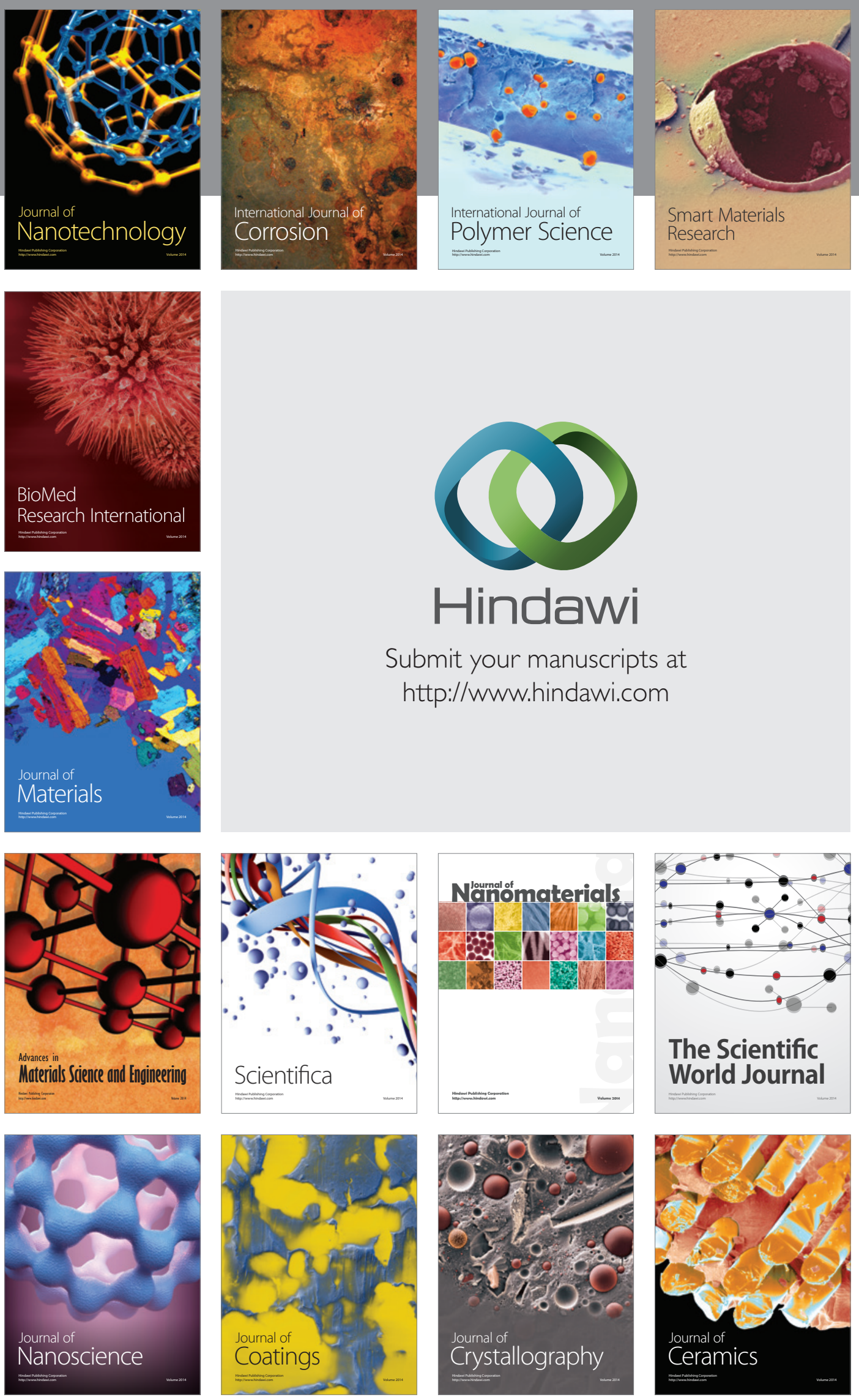

The Scientific World Journal

Submit your manuscripts at

http://www.hindawi.com

\section{World Journal}

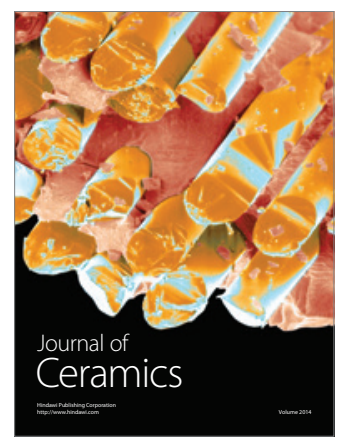

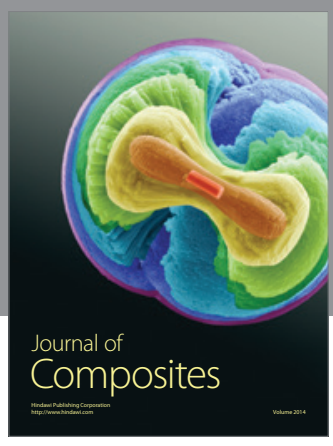
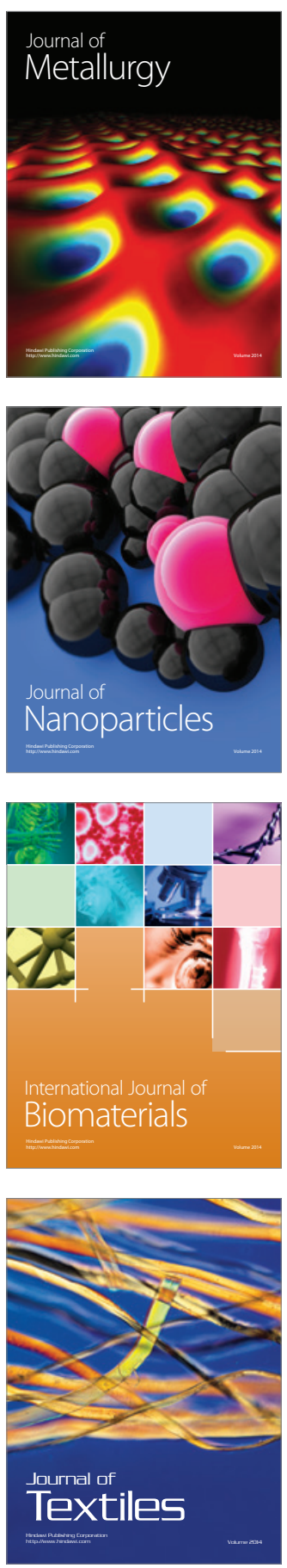